Revista Iberoamericana, Vol. LXXIII, Núm. 220, Julio-Septiembre 2007, 453-469

\title{
LOS MUISCAS Y LA MODERNIDAD: CAPITALISMO Y SUBJETIVIDADES COLONIALES EN EL NUEVO REINO DE GRANADA, SIGLOS XVI Y XVII
}

POR

Luis Fernando Restrepo

Universidad de Arkansas

El examen de culturas regionales como las culturas andinas se arriesga a naturalizar las culturas en cuestión tanto como a reproducir el esquema de diferenciación geopolítica que se estableció a partir de la colonización, que abre la era moderna. Para salvar esta trampa ideológica, es preciso elaborar un regionalismo crítico que examine cómo, a partir del siglo xvi, los Andes fueron forzosa, incompleta y desigualmente integrados al sistema mundo moderno. Se trata de una mirada atenta a las especificidades regionales que no desconoce los procesos más globales que enmarcan el devenir histórico local. Tal perspectiva, igualmente ha de prestar atención a las geopolíticas actuales que enmarcan la producción de conocimiento sobre áreas como la andina.

Este ensayo se enfoca en los muiscas, también llamados chibchas, durante el primer siglo de colonización (1537-1650). Se trata de ver la cultura muisca no como premoderna, lo cual implicaría asumir la modernidad como el único camino para el devenir histórico. Nos interesa en cambio ver a los muiscas como coetáneos de la modernidad, con la cual establecen una relación compleja. Asimismo, no se trata de una búsqueda nostálgica de nativos puros sino de ver las múltiples transformaciones de la sociedad muisca en la colonia y el dinámico proceso de dominación colonial en el cual las sociedades andinas no son víctimas pasivas sino sujetos históricos que responden de diversos modos a la violencia colonial.

El sujeto moderno como ser histórico puede ser rastreado a partir de su aparición en los códigos legales, como bien señala Michel Foucault en "La verdad y las formas jurídicas” (161). ${ }^{1}$ En los estudios andinos, Frank Salomon ya ha señalado la importancia de tomar como punto de partida los procesos de inscripción del indígena en el archivo y las transformaciones de la memoria y conciencia andinas al ser vertidas en códigos occidentales (253). En este estudio nos enfocamos específicamente en la legislación

\footnotetext{
${ }^{1}$ En Myth and Archive (1990) Roberto González Echeverría discute la importancia de la retórica legal en la formación de la literatura latinoamericana. Este crítico argumenta que El carnero (1536) de Juan Rodíguez Freyle es una obra literaria que critica, mediante la parodia, el sistema legal español (91). Al centrarse sólo en lo literario de El carnero, González Echeverría deja por fuera completamente lo relativo a los muiscas, un tema abordado por la crónica colonial, como bien lo señala Álvaro Félix Bolaños (217). A mi modo de ver, Freyle deja intacto o incluso refuerza el orden español en lo concerniente al estatus jurídico del indígena.
} 
laboral de Indias, en la cual surge el "indio” como un "vasallo libre”, un oxímoron que revela de por sí las contradicciones del proyecto de la modernidad y oculta la violencia del capitalismo que funda. Se intenta de este modo dar una mirada crítica del discurso económico, el cual es, como saber occidental, arte y parte del proceso colonizador.

\section{I}

Entrado el siglo xvI, los muiscas eran uno de los mayores grupos indígenas de los Andes nororientales en lo que es actualmente el centro de Colombia. ${ }^{2}$ Su población estaba organizada en un conglomerado de señoríos o sijipcuas de diversa extensión e importancia. Sobresalían dos jefes máximos, el Zipa en la región de Bogotá y el Zaque en Tunja. El Zipa era el más poderoso de los dos y para la época de la invasión española tenía bajo su control unos cien señoríos y venía adelantando una campaña de expansión militar en el territorio del Zaque (Villamarín y Villamarín 585; Simón 3: 425). Martha Herrera Angel ha hecho un cuidadoso rastreo de los principales nueve señoríos muiscas. ${ }^{3}$ Cada uno de estos grandes señores tenía bajo su control diferentes pueblos o parcialidades. Carl Langebaek afirma que existían además varios grupos muiscas independientes como Moniquirá, Ráquira y otros al noroccidente y los teguas al suroriente (Mercados 34-39). En conjunto, estos grupos tenían una compleja red de relaciones políticas y económicas con diversos grupos en la región como los panches, carare, guanes, laches, muzos y otros. En síntesis, tenemos una sociedad de gran complejidad que no siempre ha sido incluida en los estudios andinos, enfocados primordialmente en las culturas quechua y aymara. Como las otras culturas andinas, los muiscas eran una sociedad primordialmente agrícola. La colonización va a trastocar sustancialmente ese elemento central de la cultura muisca, a través de la imposición de mita urbana y minera, los obrajes y otras formas de trabajo.

Los españoles invadieron el territorio muisca en 1537. Para ese entonces, con las conquistas del Caribe (1492), México (1519) y el Perú (1533) ya se habían definido los patrones de colonización española: la ocupación militar, el saqueo, la fundación de ciudades españolas, el "repartimiento" de indígenas entre los miembros de la hueste para exigirles tributos y forzarlos a trabajar en las minas, haciendas y ciudades, así como las campañas contra las creencias americanas y la imposición de la religión cristiana. Se había incorporado de este modo a las Indias Occidentales al circuito mediterráneo del capitalismo mercantil.

Jurídicamente, el estatus del "indio" -como se lo designó en la época-y el derecho de España sobre las Indias estaba siendo disputado. La famosa relectio "De indis” del teólogo Francisco de Victoria es de este mismo año de la invasión del territorio muisca, 1537. Hasta este entonces, el dominio de las Indias y el derecho sobre los indios de la

\footnotetext{
${ }^{2}$ Para información general sobre los muiscas véanse Ghisletti; Broadebent Los chibchas; Hernández Rodríguez; Langebaek Mercados y Noticias; Herrera Angel; varios estudios más recientes se encuentran en el Boletín del Museo de Oro (Bogotá).

${ }^{3}$ Los principales señoríos muiscas hacia 1470 eran: Guanetá, Tundama, Sogamoso, Zaque (Tunja), Ebaté, Zipa (Muequetá) y Fusagasugá (Herrera Angel 31). Véase también Falchetti y Plazas de Nieto.
} 
corona española se basaba en la “donación” hecha por la bula papal Inter Caetera (1493) de Alejandro VI. Sobre esta bula estaban basados el requerimiento (1514) así como las Ordenanzas sobre el buen tratamiento de los indios de 1526. Dentro de este orden, el indio era considerado un ser libre, mas sólo al reconocer a la corona y la Iglesia católica. Al aceptar el requerimiento, el indio era reconocido como un vasallo libre y dueño de sí y su propiedad: "Vos reçibiran con todo amor y caridad, y vos dexaran vuetras muxeres, hijos y haziendas libres sin servidunbre, para que dellas y de vosotros hagays libremente todo lo que quisieredes" (Morales Padrón 339). El orden que se quería imponer no era una improvisación de la corona sino que tiene claros antecedentes en las comunidades musulmanas (aljamas) bajo dominio castellano, las cuales mantenían cierta autonomía, como bien lo ha señalado Patricia Seed en Ceremonies of Possession (1995). No obstante, este lenguaje de "amor" y "caridad" de la corona expresa una nueva racionalidad colonizadora que legitimaba el uso de la violencia (Rabasa 41).

La legitimidad de la conquista del Nuevo Reino de Granada no fue clara desde el principio ya que a la sabana de Bogotá llegaron independientemente tres huestes: la de Ximénez de Quesada desde Santa Marta, la de Sebastián de Belálcazar desde Quito, y la de Nicolás de Federmán desde Venezuela. Entre los miembros de estas expediciones se “repartieron" las diferentes comunidades muiscas, tocándole las mayores a los principales capitanes de las expediciones (Avellaneda 138). La encomienda dio gran poder a un reducido número de españoles al tener bajo su control a la población indígena, a la cual impusieron tributos (la demora) y obligaron a trabajar en sus casas, estancias y en las minas, creando una clase de aspiraciones señoriales como bien puede verse en las Elegías de claros varones de Indias (1589-1601) de Juan de Castellanos (Restrepo Un nuevo). De este modo, el monopolio de la fuerza de trabajo indígena ponía a los encomenderos en el centro de la sociedad colonial y les devengaba una gran riqueza. En el transcurso del primer siglo de colonización, la corona y sus representantes locales (la audiencia y los corregidores) tratarían de numerosas maneras de contrarrestar el poder de los encomenderos. Esto lo harían, sobre todo, asumiendo la tutela del indígena y rompiendo el monopolio encomendero sobre la fuerza laboral indígena, lo cual terminó poniendo a los indígenas a disposición del mercado laboral capitalista. Los resultados, sin embargo, fueron otros, frustrando así la política moderna de conformación de una fuerza laboral libre. En realidad, ésta pasa a conformarse en relaciones semiserviles en las haciendas, donde se radicarían muchos indígenas junto con mestizos, mulatos, blancos pobres y otros “agregados” (Bejarano 12).

II

La transformación del indígena tributario de la encomienda al jornalero asalariado, peón o inquilino de las haciendas ha sido ampliamente estudiada en la historiografía colombiana. ${ }^{4}$ Esta historiografía, sin embargo, ha sido primordialmente una historia institucional, enfocada en la encomienda, la mita, la esclavitud, la hacienda, el resguardo

\footnotetext{
${ }^{4}$ Véanse por ejemplo Fals Borda; González; Friede El indio; Broadbent; Ruiz Rivera; Eugenio Martínez; Colmenares; Villamaría; Avellaneda.
} 
indígena, el concierto agrario, etc. Estos enfoques impiden ver todo aquello que se desarrolla por fuera de las instituciones coloniales, como bien señala Jesús Antonio Bejarano:

Lo que la historia social de los años setenta rompe es justamente esta imagen de inmovilidad y de rigidez interna de la estructura colonial. Al hacer un mayor énfasis sobre la estructura productiva, sobre la conformación de la hacienda, sobre las relaciones entre la apropiación de la tierra y las formas de trabajo, sobre el impacto económico del mestizaje, lo que se descubre es una sociedad dinámica, donde la diferenciación social es mucho más compleja y la fuerza de trabajo mucho más móvil y más estratificada, de modo que ese movimiento acaba sobrepasando el ordenamiento institucional, y abriendo el camino a transformaciones futuras de las relaciones de trabajo en el campo. (11)

Este enfoque en los procesos históricos, en la participación de sujetos históricos concretos, sin duda nos da una visión más dinámica del ejercicio del poder que (re)produce la sociedad colonial.

Otro enfoque que permite ver la complejidad del proceso colonial es el análisis del discurso. Desde esta perspectiva se revela una historia nada inmóvil, sino donde la lucha por el poder se da en el lenguaje así como en otras prácticas simbólicas, tales como rituales, arquitectura, vestimenta, etc. Desde la aparición del libro Orientalism (1978) de Edward Said, los llamados estudios poscoloniales han revelado cómo los procesos discursivos han sido parte integral de la colonización. Un aspecto clave en los estudios poscoloniales es su alta reflexividad, la cual los lleva a cuestionarse en qué modos las formas de saber actuales, incluyendo la propia crítica poscolonial, constituyen un discurso colonial. Esta perspectiva permite, por ejemplo, ver críticamente el discurso económico en contextos de colonización. Al respecto, Jean Baudrillard y Dipesh Chakrabarty nos ofrecen perspectivas críticas bastante provechosas.

Karl Marx es sin duda uno de los principales fundadores de un discurso crítico sobre el capitalismo. Ahora bien, es preciso cuestionarse si la perspectiva del propio Marx y de la crítica marxista posterior puede dar cuenta adecuadamente de los procesos coloniales y de los fenómenos económicos en sociedades no occidentales. ${ }^{5}$ Donde Marx más se acerca a estos temas es en los capítulos finales de El capital. Allí discute los procesos históricos de la formación del capital occidental. En el capítulo titulado "La llamada acumulación primitiva” (Cap. XXVI), plantea la génesis del capitalismo como el producto del encuentro entre dos tipos de propietarios:

On the one hand, the owners of money, means of production, means of subsistence, who are eager to increase the sum of values they possess by buying other people's labour power; on the other hand, free labourers, in the double sense that neither they themselves form part and parcel of the means of production, as in the case of slaves, bondsmen, etc., nor do the means of production belongs to them, as in the case of peasant proprietors. (354)

\footnotetext{
${ }^{5}$ Existe en Latinoamérica una tradición de lecturas críticas de Marx. Está el caso andino de José Carlos Mariátegui, por ejemplo. Dos trabajos recientes son The Magical State (1997) de Fernando Coronil y Sequencias Brasileiras (1999) de Roberto Schwarz.
} 
Si bien en los siguientes capítulos Marx ofrece puntos iluminadores sobre el proceso de proletarización del campesinado (Cap. XXVII) y la violencia del capitalismo en contextos coloniales (Cap. XXXIII), es preciso ver los límites de su propuesta. En The Mirror of Production (1975) Jean Baudrillard ha señalado que pese a que Marx formula una crítica frontal a la economía política, sus planteamientos, en última instancia, están expresados dentro de la misma lógica del discurso económico europeo. Las abstracciones del discurso ilustrado son violentamente usadas para entender sociedades no occidentales. Tómense por ejemplo los conceptos de producción y trabajo, ambos presentes en el párrafo de Marx citado anteriormente. ¿Hasta qué punto puede hablarse de una "producción" agrícola andina? Además, ¿qué no alcanza a captar dicha conceptualización? El trabajo (mano de obra / labor) es una abstracción clave para la economía política. Baudrillard afirma:

This abstraction is precisely what creates the problem. At the same time that it produces the abstract universality of labor (of labor power), our epoch produces the universal abstraction of the concept of labor and the retrospective illusion of the validity of this concept for all societies. (85)

En una forma similar, el historiador Dipesh Chakrabarty resalta el eurocentrismo del concepto de trabajo (labor) en su libro Provincializing Europe (2000). Chakrabarty señala los límites de la historiografía marxista, la cual, al presuponer un sujeto secular, difícilmente puede dar cabida a eventos históricos donde participan dioses, espíritus y poderes supranaturales (72). ${ }^{6}$ Pero la propuesta de Chakrabarty no es abandonar a Marx, sino plantear lecturas críticas para abordar más adecuadamente situaciones coloniales. En este sentido, Chakrabarty hace una importante lectura del concepto de trabajo de Marx, al examinar cómo dicho concepto reconoce la diferencia política, clave para el análisis de contextos coloniales. La abstracción del trabajo es lo que hace posible el intercambio de mercancías, que son producidas por sujetos históricamente diferentes:

The question for Marx was: If human beings are individually different from one another in their capacity to labor, how does capital produce of this field of difference an abstract, homogeneous measure of labor that makes the generalized production of commodities possible? (91)

Hay entonces una tensión interna en el concepto de mercancía, entre el trabajo “real” y su abstracción, de elementos inconmensurables que presentan un reto para el historiador o crítico poscolonial para dar cuenta de la diferencia colonial (92).

\footnotetext{
${ }^{6}$ Pese a la presencia de espíritus y otras fuerzas mayores, Chakrabarty considera central el discurso secular en la negociación política ya que las demandas por la justicia social ante el Estado moderno se dan en dicha forma. El caso no es así en Colombia ni en Latinoamérica. En el actual conflicto entre los U’was y la empresa petrolera Occidental, el argumento central es el carácter sagrado del subsuelo. Igualmente, José Rabasa discrepa con el punto de vista de Chakrabarty al asumir este último que los subalternos no pueden habitar y operar dos mundos al mismo tiempo, y necesitan la ayuda del intelectual occidental(izado) (275).
} 
Una diferencia esencial al abordar culturas como la muisca es que la división sujeto/ objeto que funda tanto la ciencia, el orden jurídico y el capitalismo modernos no se da de la misma forma en el caso andino, donde hay una intricada relación que define el lugar de los seres humanos en la naturaleza y el cosmos que no se borra completamente con la conquista. Esto se puede ver en el papel mediador de los caciques en la protección de las cosechas, garantizando suficiente agua y evitando sequías y heladas, una práctica que continúa aún bajo el dominio español. En contraste, Marx y en general la cultura occidental asumen por ejemplo una visión antagónica entre el hombre y la naturaleza: "Labour, is, in the first place, a process in which both man and Nature participate, and in which man of his own accord starts, regulates, and controls the material reaction between himself and Nature” (85). Pero los muiscas pos conquista, como lo harán muchos grupos indígenas, entran en relaciones capitalistas, donde la naturaleza (los cultivos) se tornan en mercancías, al producir, por ejemplo, trigo para las minas. Esto, sin embargo, no borra completamente la forma andina de pensar la naturaleza. El resultado es una relación ambivalente y con frecuencia contradictoria con la naturaleza.

La historiografía sobre el Nuevo Reino de Granada y los trabajos etnohistóricos sobre los muiscas operan sobre varios de los supuestos del discurso económico occidental, en particular por asumir el macrorrelato del capitalismo según el cual se presenta la sociedad capitalista burguesa industrializada como el devenir natural de la historia de todas las sociedades. Por ejemplo, en su riguroso trabajo sobre los muiscas, Guillermo Hernández Rodríguez comenta que estos no tuvieron moneda en el sentido moderno. Afirma que la moneda "implica una abstracción de carácter intelectual de que sólo pueden ser capaces sociedades más desarrolladas” (63). El discurso desarrollista lo lleva consecuentemente a ver la cultura muisca en términos negativos, pero inscrita dentro del telos del capitalismo: "la ausencia del espíritu de lucro en las transacciones, la escasez de una producción en grande escala, son circunstancias que en las sociedades como la chibcha retardan el aparecimiento de la moneda como medida universal del valor” (Hernández Rodríguez 64). La temporalidad occidental se impone sobre la andina, al inscribirla, “retardada”, en el relato del progreso capitalista. Otros autores, como Julián Ruiz Rivera también asumen la inferioridad o el retraso andino simplemente por no presentar el mismo desenvolvimiento que la sociedad metropolitana. Su libro Encomienda y mita en Nueva Granada (1975) es un trabajo esmeradamente bien documentado. Sin embargo, su visión de lo andino es sumamente pobre. Tras afirmar la superioridad técnica castellana en la agricultura, la producción textil y la construcción, Ruiz Rivera afirma:

Por su parte los indios y sus jefes no conocían otro mundo que el propio, reducido en aspiraciones y conocimientos. Sus jerarquías de valores diferían de aquellas de los blancos. Un ejemplo claro es su concepto de los metales preciosos, que utilizaban incluso para fabricarse yelmos y corazas. Del holgado ritmo de producción, suficiente para asegurar la subsistencia, pasaron a sufrir el constante acoso de quienes buscaban una ganancia. (306)

Por otra parte, María Ángeles Eugenio Martínez examina la legislación laboral de la colonia desde la perspectiva del Estado racional moderno. En Tributo y trabajo del indio 
en Nueva Granada (1977) Eugenio Martínez presenta la legislación imperial como un proceso de gradual reconocimiento de los derechos indígenas, del servicio personal al régimen contractual (336). La supresión de los tamemes (uso de los indígenas como cargadores), los servicios personales, la reglamentación de la mita y el alquiler, son sin duda esfuerzos racionalizadores de la explotación. No obstante son parte de un proceso colonizador mediante el cual se afirma el Estado a través de la producción de sujetos indígenas que requieren su defensa.

El riguroso trabajo económico del historiador Germán Colmenares sigue teniendo gran valor y vigencia en la actualidad. Su ya clásica Historia económica y social de Colombia, 1513-1719 (1975) nos ilustra la importancia de la encomienda en la primera fase de la colonización. En cuanto al trabajo agrícola, se describe con propiedad la transición de la encomienda al régimen salarial (163-75). No obstante, es un trabajo desde la perspectiva del desarrollo del capitalismo, donde la visión indígena de la encomienda, la mita, el concierto agrario están ausentes. Esta ausencia es algo que con cierto éxito aborda Sylvia Broadbent en "The Formation of Peasant Society in Central Colombia" (1981) al examinar las estructuras muiscas a lo largo de la colonia e incluso hasta el principio de la República, cuando se deshicieron los resguardos. Broadbent muestra que hasta entrado el siglo XIX, los registros civiles indígenas siguen llevándose a cabo de acuerdo a patrones muiscas, esto es en términos de "partes” o "parcialidades” (268). Un trabajo clave por su rigurosa documentación, su postura crítica ante las propuestas desarrollistas y su distancia ante las teorías occidentales es El hombre y la tierra en Boyacá (1973) de Orlando Fals Borda. Este sociólogo critica, por ejemplo, el "desarrollismo represivo” del Estado colombiano como los proyectos del INCORA (Instituto Colombiano de la Reforma Agraria) que limitan considerablemente las propuestas de cambio del pueblo (19). Para Fals Borda, la experiencia colonial de los resguardos es considerada clave en un proyecto de autogestión campesina:

En el caso boyacense no es necesario buscar las fórmulas de autogestión en textos e ideólogos europeos. Por fortuna el pueblo campesino trabajador cuenta allí con una rica tradición comunal y de resguardos que, aunque adormecida, puede revivir para hacer frente a sus actuales enemigos de clase, si se aplican las técnicas adecuadas que en otra parte hemos llamado de "recuperación crítica”. (23)

En suma, los diversos estudios sobre la historia económica muisca y colonial, si bien brindan valiosos aportes sobre muchos aspectos, no cuestionan a fondo el asumido telos del capitalismo y las categorías críticas empleadas para su análisis tales como producción, mano de obra, capital, etc. También se caracterizan estos estudios por la poca problematización del sujeto como construcción histórica y discursiva. Por último, es evidente que no dan suficiente cuenta de aquello que marginó o suprimió la historia hegemónica, es decir la historia desde la perspectiva subalterna. Para los muiscas pos conquista, ¿qué significaba, por ejemplo, el tributo (tamsa), el trabajo (choque), concertar, contratar o alquilar (zefuchugosqua, utafihistuc), la encomienda, la mita y otros términos relacionados con el trabajo indígena? Sin duda, el problema clave para poder dar cuenta de la visión subalterna de la colonización radica en gran parte en la documentación 
disponible. Y donde la hay, como lo vemos en los memoriales de agravios y en las intervenciones indígenas en el ámbito legal, es preciso tener en cuenta que dichas voces surgen principalmente a través del discurso colonial, donde el espacio del otro está predeterminado por la lógica misma del discurso. Si bien esta barrera discursiva parece ahora insoslayable, un examen crítico de los límites del saber occidental, así como los límites de sus disciplinas y sus herramientas teóricas pueden contribuir a la creación de una epistemología posoccidental (Mignolo).

III

Las crónicas y la documentación colonial indican que entre los muiscas había una identidad corporativa expresada mediante el nombre del cacique o capitán. En efecto, el nombre de la autoridad indígena designaba tanto la tierra como la comunidad. Estas unidades señoriales jerárquicamente organizadas fueron mantenidas en gran parte por los españoles como estrategia de dominio, pero también fueron reafirmadas por los propios muiscas para defender sus intereses, como puede verse en los memoriales de agravios donde el cacique o capitán abogaba por toda la comunidad. Lo que me interesa resaltar es cómo la legislación laboral aborda y transforma esta identidad corporativa. La legislación contradictoriamente busca imponer un sujeto compatible con el orden capitalista y su sentido de propiedad privada pero por otro mantiene formas comunales como el resguardo (tierras asignadas para el beneficio de cierta comunidad) y crea nuevas comunidades mediante las “reducciones", donde se agrupaban varios grupos indígenas, no siempre de la misma etnia.

El establecimiento de un orden jurídico que legitimara universalmente el capitalismo requería concebir a todos los seres humanos como entes libres con derechos sobre la propiedad. De este modo es concebido el indio por la legislación española. Desde este punto de vista, el indio es, paradójicamente, uno de los primeros sujetos modernos. Como tal, en él se revelan las contradicciones de la modernidad, pues simultáneamente es inscrito a través de un discurso colonial que lo subordina, que busca disciplinarlo y hacerlo productivo. Es decir: donde la libertad abstracta es confrontada por las diferencias concretas que crean las condiciones de generación del capital; ese encuentro cara a cara que describe Marx, entre dos propietarios, uno de los cuales tiene los medios para comprar el trabajo del otro y este último es "libre” de venderlo:

The immediate producer, the labourer, could only dispose of his own person after he had ceased to be attached to the soil and ceased to be the slave, serf, or bondman of another. To become a free seller of labour power, who caries his commodity wherever he finds a market. (355)

El movimiento histórico que transforma a los productores en asalariados, afirma Marx, es visto como un proceso de emancipación por la historiografía burguesa, la cual sólo presenta una cara de la moneda. Lo que queda fuera de dicha historia es el proceso mediante el cual ellos han sido despojados de sus medios de producción. Esta parte de la historia está escrita con fuego y sangre, dice Marx (355). Veamos cómo la legislación 
española presenta al indígena como ser libre, así como a través de diferentes modos busca transformarlo en un sujeto productivo y disciplinado.

En el debate de la escuela de Salamanca se afirmó la libertad del indígena y su derecho de propiedad a partir del concepto dominium, proveniente del derecho romano. El dominio designaba la propiedad privada, la libertad de acción e incluso el derecho sobre el propio cuerpo (Pagden 80-1). El teólogo Francisco de Victoria refutaba el derecho papal de donar las Indias a España ya que antes del "descubrimiento" los indios pacíficamente tenían dominio privado y público sobre sus cosas (82). Este dominio sólo podía ser refutado por cuatro causas: por ser pecadores, por ser infieles, por no tener uso de razón (insensati) o por ser idiotas (amentes). El debate, que sólo podemos discutir brevemente aquí, se centró sobre las primeras tres causas. Victoria, por ejemplo, afirmaba que ni el canibalismo ni el sacrificio humano despojaban a los indígenas de su humanidad y por lo tanto de su derecho de dominium (84). Para Juan Ginés de Sepúlveda, en contraste, el canibalismo y el sacrificio americanos eran más que actos individuales, actos de toda una sociedad contra la ley natural y la humanidad, y por esto podía hacerse justa guerra contra los indios así como despojarlos de sus personas y propiedades. Además, Sepúlveda argumentaba que el dominio de las cosas es limitado. El canibalismo, el sacrificio humano y el uso del oro para las idolatrías constituían un abuso del dominium; por lo tanto se justificaba revocar sus derechos naturales (92). En diversas formas, los argumentos de Sepúlveda y la legitimidad política de la conquista fueron debatidos por de las Casas y los discípulos de Victoria, quedando injustificada la privación del derecho de dominium de los indígenas sobre sus personas y bienes. Como resultado, este concepto jurídico fundamenta las Nuevas Leyes (1542) así como la legislación laboral del Nuevo Reino de Granada, pero como veremos, en el proceso colonizador entra mucho más en juego que el racionalismo jurídico. Pese al sentido proteccionista de los derechos nativos, la imposición del concepto europeo de dominium es parte esencial de la colonización de los indígenas.

La empresa colonial generó un extenso archivo sobre las cuestiones indígenas. Como es bien sabido, la tradición legal ibérica es casuística, y tuvo como resultado la creación de un corpus legal que buscaba adecuarse a los contextos locales. Teniendo esto en cuenta, me enfoco en algunos ejemplos de la legislación laboral referente al Nuevo Reino de Granada donde aparece el tema del indio como sujeto libre. Desde las Nuevas Leyes (1542) la corona ordenaba que los indios fuesen "muy bien tratados e ynstruydos en las cosas de nuestra sancta fee cathólica y como vasallos nuestros libres” (Ordenanza XXX; Morales Padrón 437). Pero es en el ámbito laboral donde más concretamente puede verse en qué radica ese estatus jurídico y qué orden social establece. Como bien se dijo, a través de la encomienda los indios quedaban bajo el dominio prácticamente privado del encomendero. La legislación imperial y sus representantes locales intentarían contrabalancear el poder de los encomenderos sobre los indígenas, creando una fuerza laboral más flexible que sirviera en los diferentes sectores de la creciente economía colonial, tales como la minería, los centros urbanos, los medios de comunicación y transporte, etc. Paradójicamente, la corona busca liberar al indígena del dominio encomendero ofreciéndole la libertad de vender su propio trabajo a quién le ofreciera la mejor compensación.

En las ordenanzas de la Audiencia de Santa Fe sobre el trabajo de los indios en las minas del 5 de septiembre de 1570 se presenta al indígena como un empresario libre: 
$1^{\circ}$. Que los dichos indios sepan y entiendan que contra su voluntad no han de ser llevados ni apremiados a sacar oro, ni piedras, ni plata ni otra cosa contra su voluntad, sino como personas libres que son, queriéndolo ellos hacer, lo han de hacer libremente y para su aprovechamiento, de manera que todo el oro o plata y piedras y otra cosa que sacaren sea para ellos mismos, pues les cuesta su trabajo para comer y vestir y sustentar su casa (Colmenares et al. 55)

La conciencia imperial de la fuerza laboral indígena como fuente de riqueza está patente en la legislación, la cual buscaba tornarlos en sujetos productivos y disciplinados. Esto lo podemos ver claramente en la instrucción real sobre el trabajo de los indios, dada el 24 de noviembre de 1601. En el preámbulo, el documento expone la razón de la legislación:

Para que los indios vivan con eterna libertad de vasallos [...] sin nota de esclavitud ni de otra sujeción ni servidumbre más de la que como naturales vasallos deben [...] que mediante el trabajo, industria, labor y granjería de los mismos indios se atienda a la perpetuidad y conservación de esas provincias, como cosa que es tan forzosa y que depende la una de la otra. (Konetzke 71)

En este fragmento es evidente la contradicción de la legislación colonial, la cual por una parte concibe un indígena libre, pero al mismo tiempo justifica su explotación como necesaria. En el primer artículo de la instrucción se obliga a los indígenas a acudir a las plazas de las ciudades para que "los concierten y cojan allí, por días o por semanas y ellos vayan con quien quisieren y por el tiempo que les pareciere, de su voluntad, sin que nadie les pueda detener contra ella” (72). Igualmente, la legislación imperial habla de la libertad de los indígenas para ir a trabajar "de su voluntad" a las haciendas y a las minas $(75,78)$. Como la igualdad de ciudadanos en la legislación política burguesa, la libertad económica del indígena es completamente abstracta, aunque necesaria para legitimar el Estado moderno. A la par de esta libertad abstracta, opera un discurso colonial que convierte al indígena en sujeto colonial productivo y disciplinado. Este discurso colonial puede verse en por lo menos cuatro instancias. A modo de contrapunto, mostraremos que los muiscas no se quedaron pasivos ante la violencia colonial y respondieron a ella de diversos modos. En numerosas instancias, los muiscas apelan a la justicia real para que se les respeten los derechos que estipulaba la legislación. Lo más probable es que no todas las respuestas muiscas se den sobre este espacio secular (lo que tradicionalmente ha mirado la historia marxista), sino que simultáneamente se estuvieran buscando mediaciones a nivel cosmológico, lo cual explicaría, por ejemplo, la importancia que adquieren en las décadas siguientes a la invasión los chuques o sacerdotes muiscas a quienes acudían los indígenas a consultar sobre enfermedades, el bienestar de las cosechas, e incluso lo que iban a hacer los españoles (Langebaek, "Resistencia” 304).

1. Por el bien de la República

Si bien la legislación consideraba al indio como un ser libre para concertarse según su voluntad, su trabajo es lo que sostiene la sociedad colonial. Ante esta situación, se 
obliga al indígena a trabajar. Esto se ve en las ordenanzas de trabajo agrícola del oidor Miguel Ibarra, dadas el 2 de septiembre de 1598: “conviene proveher acudan a la labor y beneficio del campo e crías de los ganados y a los tratos y comercio de la tierra para que el comercio no se pierda y los mantenimientos aya abundanzia” (Colmenares La provincia 237). Este mismo argumento está presente en varios artículos de las instrucciones reales de 1601. Por ejemplo, el artículo noveno dice:

La conservación de esas provincias y de los mismos indios y la de estos reinos depende, como sabéis, en el estado presente, principalmente de la labor y beneficio de las minas de oro y plata, lo cual estoy informado que en ninguna manera se puede hacer sin la industria y trabajo de los indios, y que por esto y estar habituados y acostumbrados en ello, en ningún caso se puedan excusar de acudir a esto. (Konetzke 78)

Los muiscas responden de numerosas formas. Muchos indígenas huyen de sus comunidades para no ir a la mita. ${ }^{7}$ En el memorial de agravios que Don Diego de Torres, cacique de Turmequé, entregó a Felipe II en 1584, se detallaban numerosos abusos por parte de los encomenderos y otros oficiales coloniales. Don Diego resaltaba que el abuso acabaría con los indígenas: "En breve tiempo quedarán yermas y despobladas de naturales aquellas provincias que han quedado como las demás se han dicho, y el Real patrimonio de Vuestra Majestad vendrá a menos porque no habiendo naturales no habrá renta ni provecho ninguno de aquella tierra” (Friede Fuentes 8:273). Es decir, Don Diego responde a la corona en los términos de ésta. Su memorial reclama derechos principalmente dentro de los parámetros del orden colonial, señalando sus contradicciones en torno al trato de los indígenas (Restrepo “Narrating...” 112).

\section{LA PROTECCIÓN DE LOS INDÍGENAS}

Es bien sabido que la corona buscó ejercer mayor control sobre las Indias al asumir el papel de protector de los indígenas. Como en la Brevísima de las Casas, en la legislación laboral se le define como un ser frágil y vulnerable que necesita el amparo real. Las ordenanzas de la Audiencia de Santa Fe de 1570 “permitían” que sólo la décima parte de cada comunidad se pudiera alquilar "porque los dichos naturales se conserven y sustenten y no se disminuya y vayan en crecimiento, por ser personas frágiles y de poco entendimiento" (Colmenares et al. 58).

Hay una gran cantidad de instancias en las cuales los muiscas se quejan ante las autoridades, utilizando el lenguaje de la propia legislación colonial como base. En 1600, los caciques de Soratá presentaron al visitador un extenso memorial de agravios donde acusaban a su encomendero Joan Rodríguez Morales de no pagarles, torturarlos, forzarlos

${ }^{7}$ En Fuentes coloniales para la historia del trabajo en Colombia, colección editada por Germán Colmenares, M. de Melo y D. Fajardo encontramos varios ejemplos, tales como las "Dilgencias encaminadas a la reducción de indios futigivos” de 1616 y 1917 en Pamplona, la Real Provisión para averiguar la sobre la fuga de indios del pueblo de Cerinza de 1628 y la fuga de más de veinticindo indios del pueblo de Guatavita que debían ir a la mina de las Lajas (Colmenares et al. 79, 84 , 95, 99). 
a trabajar incluso los domingos e impidiéndoles ir a misa, ocuparles las tierras y otros cargos. Los caciques apelaban a la protección del Estado colonial: “Como myserables ya no podemos llevar tanta carga de agravios y malos tratamyentos” (Colmenares La provincia 242).

\section{Disciplinamiento}

El indígena es considerado libre por la legislación colonial. Por su propia voluntad, debería amar el trabajo y realizarlo diligentemente. Esto es lo que asume el discurso imperial. Entretanto no haya esta "voluntad" el Estado se ve forzado a compeler a los indígenas a trabajar (también a blancos vagos, negros, mestizos, mulatos y otros grupos subalternos). ${ }^{8}$ Se caracteriza al indígena como carente de una ética capitalista del trabajo, como lo expresan los miembros del Consejo de indias en 1596: "Y porque, naturalmente, todos los indios son inclinados a vicios y borracheras y ser holgazanes, sin aplicarse de su voluntad a ningún género de trabajo aún al de la labor de sus tierras para su propio mantenimiento y sustento, ni tienen fin de adquirir haciendas” (Konetzke 45). El Consejo recomienda entonces que se dé orden para que "vivan en policía y comercio como gente de razón” (46). Es decir se asume el capitalismo como la única forma válida de existencia: fuera de la razón capitalista está la barbarie. En similar forma se describe al indígena en las ordenanzas de Ibarra (1596), las instrucciones reales de 1601 y otros documentos. ${ }^{9}$

Serán múltiples los esfuerzos por disciplinar al indígena. Con este fin se concentran en pueblos donde pueden ser mejor supervisados por las autoridades coloniales. Sin embargo, pese a que las autoridades coloniales se esforzaron por relocalizar a los muiscas en pueblos nucleados, son múltiples las ocasiones durante los siglos XVI, XVII y XVIII en las cuales estos abandonan los nuevos pueblos y se relocalizan junto a sus estancias y labranzas dentro de los resguardos (Herrera 53).

\section{INDIVIDUALIZACIÓN}

Sin duda uno de los procesos que más hondamente transformó la sociedad muisca fue el proceso de individualización. Esta transformación es patente en la legislación laboral y en particular en relación a los salarios. Aunque la corona mantuvo muchos aspectos de la organización tradicional muisca, como la división en las partes y parcialidades muiscas

\footnotetext{
${ }^{8}$ Las instrucciones reales de 1601 compelían a los indígenas a trabajar y también ordenaban "que de la misma manera sean compelidos los españoles de condición servil y ociosos que hubiere y los mestizos, negros, mulatos y zambaigos libres, para que todos trabajen” (Konetzke 72).

${ }^{9}$ Una real cédula del 28 de julio de 1578, por ejemplo, versaba así: "Proveeréis en todas las provincias subjetas a esa Audiencia que los indios que fueren oficiales entiendan y se ocupen en sus oficios y que los que fueren labradores que cultiven y labren la tierra y hagan sementeras par sí mismos, como tengan mantenimientos para sí y le quede para vender y haya en esa provincia cumplimiento de mantenimientos y que los mercaderes entienden en sus tratos y mercadurías. Y los indios que en ninguna cosa de los susodicho se ocupan, daréis orden que se alquilen para trabajar en labores de campos y obras dela ciudad y para ello si fuere necesario, los compeleréis de manera que no estén ociosos” (Colmenares et al. 196).
} 
y el respaldo a las autoridades locales, por ejemplo, en la legislación laboral se iría minando el sentido corporativo de la sociedad muisca, concibiendo un sujeto independiente, cuya autonomía permitiera su incorporación al mercado laboral. Esto es patente en la real cédula del 28 de julio de 1578 donde el contrato laboral suprime la jerarquía nativa: “y daréis orden como les paguen el jornal de su trabajo a los mismos indios que trabajaren y no a sus principales ni a otra persona alguna” (Colmenares et al. 196). El pago individualizado también incorpora a la mujer en el mercado capitalista, como bien puede verse en las ordenanzas de Ibarra (1598) donde se estipula la paga para las mujeres que desempeñaban trabajos junto a sus maridos o en el servicio de casas o estancias. La paga era claramente desigual. A los indios de los molinos, por ejemplo, se les pagaba trece pesos de oro al año, un sombrero y seis pares de alpargatas. A sus mujeres se les pagaba dos mantas de algodón y un maure al año. Cada uno recibía además media fanega de maíz por quincena (Colmenares La provincia 239-40).

Otro proceso de individualización de la sociedad muisca tiene que ver con la forma en que se recolectaban las cosechas. En esta época, las comunidades muiscas asistían a las labranzas en conjunto, familias enteras. Los españoles optaron por mantener este sistema y así sólo pagaban al cacique o persona principal y éste se encargaba de distribuir la paga entre la comunidad. En su visita al valle de Tenza, el oidor Antonio de Obando consideró que esta forma de remuneración era injusta pues, según sus cuentas, muy poco le tocaba a cada uno de los trabajadores. Además, las ganancias también servían para pagar la demora (tributo) de los indígenas ausentes. Por esto Obando prohibió el trabajo común y ordenó que se le pagara a cada indígena, hombre, mujer o muchacho, por igual, a cuatro tomines de plata por semana (Colmenares et al. 225-7). Las indicaciones de Obando fueron resistidas o ignoradas, y la costumbre de concertar la recolección en conjunto continuó.

Por otra parte, es importante reconocer que el proceso de individualización presentó nuevas opciones para los muiscas, si bien no siempre favorables a largo plazo para la comunidad en sí. Apremiados por los tributos y quizás por la presión de sus caciques, muchos indígenas optaron por hacer la vida en las ciudades españolas, en diferentes oficios, en el transporte de mercancías y otras formas de ganarse la vida. El establecimiento de los resguardos, por otra parte, fortaleció una tradición comunal que se mantendría latente hasta el siglo xx, a pesar de la abolición de los resguardos y de los valores burgueses del minifundismo en la región (Fals Borda).

IV

Dos siglos antes de la proclamación francesa de los Derechos del Hombre, en España se produjo una reflexión mucho más amplia sobre los derechos humanos, aunque poco conocida más allá del campo de los estudios hispánicos. Como bien ha señalado Walter Mignolo, la proclamación francesa planteaba los derechos políticos en términos de los Estados soberanos europeos (30). La reflexión española, en contraste, surgió en directa relación con la experiencia colonial, y buscaba crear un marco político para conformar un sistema que integraba diferentes territorios y sociedades multiétnicas. Por esto mismo, la 
experiencia española del siglo Xvi constituye un importante punto de partida para pensar críticamente la modernidad y la actual globalización. Sin duda uno de los aportes de la experiencia ibérica fue mostrar tempranamente las contradicciones del proyecto de la modernidad. Esto lo vemos en la legislación laboral, donde el “indio" como sujeto moderno, abstractamente igual a los demás seres humanos y dueño de sí mismo, su cuerpo y propiedad, surge contradictoriamente a la par de un discurso colonial que lo subordina, lo explota y lo despoja de sus bienes. Pero las sociedades andinas en ningún modo aceptan pasivamente la colonización y responden en múltiples formas a la modernidad. El hecho de que el idioma muisca haya desaparecido hoy día es cierto, pero las comunidades rurales en la región nunca desaparecieron. El hecho de que no se identifiquen como indígenas bien puede ser parte de un proceso de "acomodamiento" que se ha visto principalmente desde el punto de vista criollo y mestizo, dentro de los macrorrelatos de la nación y la modernidad. Al romper con estos macrorrelatos, se abre la puerta para la descolonización de la memoria muisca, no como una búsqueda nostálgica sino como parte del proceso de apertura de la sociedad actual. Por ejemplo, esto tiene directa relación con la situación de los U’wa (tunebos) hoy día. Esta etnia, relacionada a los muiscas, ha estado librando hace años una contundente lucha por recuperar sus tierras y contra una empresa petrolera estadounidense (la Occidental de Colombia) y el gobierno colombiano que ha aprobado la explotación del subsuelo. ${ }^{10}$ Su intervención, en todo caso, incumbe mucho más que a un reducido grupo de indígenas, pues se replantea el modelo de Estado y de desarrollo capitalista; en otras palabras, se confronta la modernidad.

BiBLIOGRAFÍA

Autoridades Tradicionales y Cabildo Mayor de la Asociación U’wa. “Comunicado”. Amazon Alliance for Indigenous and Traditional Peoples of the Amazon Basin, Washington, D.C., 7 de mayo de 2002.

Avellaneda, José Ignacio. The Conquerors of the New Kingdom of Granada. Albuquerque: University of New Mexico Press, 1995.

\footnotetext{
${ }^{10}$ El testimonio U’wa de Berichá, Tengo los pies en la cabeza (1992), habla del proceso de organización política de la etnia a partir de la conformación de los cabildos indígenas. Los cabildos no existían entre los U’was y su adopción es una forma positiva de transformación para resistir la colonización. Otras etnias los asesoraron jurídicamente para establecerse y tener amparo bajo la legislación nacional (Berichá 42). En el comunicado del 7 de mayo de 2002 de las autoridades tradicionales y Cabildo Mayor de la Asociación U’wa, el debate político no se limita al ámbito de lo secular y revela una concepción de la naturaleza diferente de la del capitalismo, ya que ésta no es vista como un objeto. También puede verse que la lucha $U^{\prime}$ wa trasciende el marco nacional al entrar en diálogo con la comunidad internacional: "Desde el año 1996 cuando llega a nuestro territorio el hermano Terence Freitas nos dio la fuerza espiritual y señaló el camino por donde debería caminar el Pueblo U'wa en su lucha contra la diabólica multinacional de petróleo Occidental de Colombia OXY que vino y violó nuestro más sagrado derecho, cometió violación en cuerpo sagrado de nuestra madre tierra, su puñalada se sintió a unos cuantos pies (12.500) debajo de la capa terrestre y ella lloró, nos pidió que la defendiéramos y que le contáramos al mundo lo que estaba sintiendo" (Comunicado U'wa).
} 
Baudrillard, Jean. The Mirror of Production. St. Louis: Telos Press, 1975.

Bejarano, Jesús Antonio. “Campesinado, luchas agrarias e historia social en Colombia”. Historia política de los campesinos latinoamericanos. Pablo González Casanova, ed. México: Siglo XXI, 1985. 3: 9-72.

Berichá. Tengo los pies en la cabeza. Bogotá: Los Cuatro Elementos, 1992.

Bolaños, Álvaro Félix. "History and Plunder in El carnero". Colonialism Past and Present: Reading and Writing about Colonial Latin America Today. Álvaro Félix Bolaños \& Gustavo Verdesio, eds. Albany: SUNY Press, 2002. 215-37.

Broadbent, Sylvia. Los chibchas: organización socio-política. Bogotá: Universidad Nacional de Colombia, 1964.

“The Formation of Peasant Society in Central Colombia”. Ethnohistory 28/3 (1981): 259-77.

Casas, fray Bartolomé de las. Brevísima relación de la destrucción de las Indias. Madrid: Cátedra, 1992.

Chakrabarty, Dipesh. Provincializing Europe. Princeton: Princeton University Press, 2000.

Colmenares, Germán. Historia económica y social de Colombia, 1537-1719. Bogotá: La Carreta, 1975.

La provincia de Tunja en el Nuevo Reino de Granada. Tunja: Academia de la Historia Boyacense, 1984.

et al. Fuentes coloniales para la historia del trabajo en Colombia. Bogotá: Universidad de los Andes, 1968.

Coronil, Fernando. The Magical State: Nature, Money, and Modernity in Venezuela. Chicago: University of Chicago Press, 1997.

“Descripción de la ciudad de Tunja en 1610”. Colección de documentos inéditos relativos al descubrimiento, conquista y organización de las antiguas posesiones españolas de América y Oceanía (CODOIN). Madrid: Real Academia de la Historia, 1868. IX: 393-451.

Eugenio Martínez, María Ángeles. Tributo y trabajo del indio en Nueva Granada (de Jiménez de Quesada a Sande). Sevilla: Escuela de Estudios Hispano-Americanos; Consejo Superior de Investigaciones Científicas, 1977.

Falchetti, Ana Maria y Clemencia Plazas de Nieto. El territorio de los muiscas a la llegada de los españoles. Bogotá: Universidad de los Andes, 1973.

Fals Borda, Orlando. El hombre y la tierra en Boyacá. 2 ed. Bogotá: Punta de Lanza, 1973.

Friede, Juan. El indio en lucha por la tierra; historia de los resguardos en el macizo central colombiano. Bogota: Ediciones La Chispa, 1972.

Fuentes documentales para la historia del Nuevo Reino de Granada. Bogotá: Banco Popular, 1976.

Foucault, Michel. “La verdad y las formas jurídicas”. El discurso del poder. Oscar Terán, ed. México: Folios, 1983. 158-73.

Ghisletti, Louis. Los mwiskas. 2 vols. Bogotá: Editorial ABC, 1954.

González, Margarita. El resguardo en el Nuevo Reino de Granada. Medellín: La Carreta, 1970. 
González Echeverría, Roberto. Myth and Archive: A Theory of Latin American Narrative. Cambridge: Cambridge University Press, 1990.

Hernández Rodríguez, Guillermo. De los chibchas a la colonia y a la República. Bogotá: Instituto Colombiano de Cultura, 1975.

Herrera Angel, Martha. Poder local, población y ordenamiento territorial en la Nueva Granada, siglo XVIII. Bogotá: Archivo General de la Nación, 1996.

Konetzke, Richard. Colección de Documentos para la historia de la formación social de Hispanoamérica. Vol. 2.1. Madrid: Consejo Superior de Investigaciones Científicas, 1958.

Langebaek, Carl. Mercados, poblamiento e integración étnica entre los muiscas, siglo XVI. Bogotá: Banco de la República, 1987. Noticias de caciques muy mayores. Bogotá: Universidad de los Andes, 1992.

"Resistencia indígena y transformaciones ideológicas entre los muiscas del los siglos XVI y XVII”. Concepciones de la Conquista. Felipe Castañeda \& Matthias Vollet, eds. Bogotá: Universidad de los Andes, 2001. 281-328.

Mariátegui, José Carlos. Siete ensayos de interpretación de la realidad peruana. México: Era, 1979.

Marx, Karl. Capital. Chicago: Enciclopedia Britannica, 1952.

Mignolo, Walter. Local Histories / Global Designs: Coloniality, Subaltern Knowledges, and Border Thinking. Durham: Duke University Press, 2000.

Morales Padrón, Francisco. Teoría y leyes de la conquista. Madrid: Cultura Hispánica, 1979.

Pagden, Anthony. "Dispossessing the Barbarian”. The Languages of Political Theory in Early-Modern Europe. Anthony Pagden, ed. Cambridge: Cambridge University Press, 1987. 79-98.

Rabasa, José. Writing Violence on the Northern Frontier. Durham: Duke University Press, 2000.

Restrepo, Luis Fernando. Un nuevo reino imaginado. Bogotá: Instituto Colombiano de Cultura Hispánica, 1999.

"Narrating Colonial Interventions: Don Diego de Torres, Cacique of Turmequé in the New Kingdom of Granada". Colonialism Past and Present : Reading and Writing about Colonial Latin America Today. Álvaro Félix Bolaños \& Gustavo Verdesio, eds. Albany: SUNY Press, 2002. 97-117.

Rodríguez Freyle, Juan. El carnero. Caracas: Ayacucho, 1979.

Ruiz Rivera, Julián. Encomienda y mita en Nueva Granada en el siglo XVII. Sevilla: Escuela de Estudios Hispanoamericanos, 1975.

Said, Edward. Orientalism. New York: Vintage, 1978.

Salomon, Frank. "La textualización de la memoria en la América andina”. América Indígena 54/4 (1994): 229-61.

Schwarz, Roberto. Sequencias Brasileiras. São Paolo: Companhia das Letras, 1999.

Seed, Patricia. Ceremonies of Possession in Europe's Conquest of the New World. Cambridge: Cambridge University Press, 1995.

Simón, Fray Pedro. Noticias historiales de las conquistas de tierra firme en las Indias Occidentales. Bogotá: Banco Popular, 1981. 
Victoria, Francisco de. De indis et de ivre belli. Relectiones. Ernest Nys, ed. Buffalo: William Hein, 1995.

Villamarín, Juan. "Encomenderos and Indians in the Formation of Colonial Society in the Sabana de Bogotá”. Diss. Brandeis University, 1972.

\& Judith Villamarín. "Chiefdoms". The Cambridge History of the Native Peoples of the Americas. Frank Salomon y Stuart Schwartz, eds. Cambridge: Cambridge University Press, 1996. 3.2: 577-667. 